American Journal of Animal and Veterinary Sciences 5 (2): 111-116, 2010

ISSN 1557-4555

(C) 2010 Science Publications

\title{
Nephrocalcinosis in Female Rats Fed Diets Containing Either Pectin or Cellulose
}

\author{
Ahmed Alhaidary, H.E. Mohamed and A.C. Beynen \\ Department of Animal Production, College of Food and Agricultural Sciences, \\ King Saud University, P.O. Box 2460, Riyadh 11451, Kingdom of Saudi Arabia
}

\begin{abstract}
Problem statement: There is evidence that the type of fiber influences the development of nephrocalcinosis in rats, but the effect of pectin was unknown. Approach: The effects of dietary pectin and cellulose on kidney calcification were studied in female rats. The diets used contained either $0.4-0.6 \%$ phosphorus and either cellulose $(10 \%, \mathrm{w} / \mathrm{w})$ or pectin. The purified diets used were balanced for residual calcium, magnesium and phosphorus in the fiber preparations. Results: Increasing the phosphorus concentration of the diet from $0.4-0.6 \%$ caused massive nephrocalcinosis in rats fed the cellulose diets. Pectin $(10 \%, \mathrm{w} / \mathrm{w})$ versus cellulose in diets containing $0.4 \%$ phosphorus significantly increased calcium and phosphorus concentrations in kidney. When compared with cellulose, pectin did not influence the apparent absorption of calcium, phosphorus and magnesium. Urinary concentrations of calcium and magnesium were not affected by pectin feeding, but those of phosphorus were increased. When pectin was given with the diet containing $0.6 \%$ phosphorus, its nephrocalcinogenic action as compared with cellulose was not observed. Conclusion: Pectin instead of cellulose in diets containing $0.4 \%$ phosphorus induced nephrocalcinosis in female rats. The effect of pectin may be explained by an increase in urinary phosphorus concentration. The lack of nephrocalcinogenic action of pectin in a diet with $0.6 \%$ phosphorus indicates that the nephrocalcinosis-inducing effect of high phosphorus intake had overruled any effect of fiber type.
\end{abstract}

Key words: Rats, nephrocalcinosis, diet, pectin, cellulose

\section{INTRODUCTION}

Nephrocalcinosis is an intratubular deposition of calcium phosphates in the corticomedullary junction of the kidney (Nguyen and Woodard, 1980). It is a common condition in female rats fed purified diets (Hoek et al., 1988), but it is sometimes seen also in female rats fed commercial, natural-ingredient diets (Ritskes-Hoitinga et al., 1991). The development of nephrocalcinosis in rats fed purified diets is further enhanced when the diets are either low in magnesium (Bunce et al., 1965), high in phosphorus (Mars et al., 1988) or high in calcium (Hoek et al., 1988). The dietinduced mineral composition of urine may determine the formation of calcium phosphate precipitates in the tubular fluid which in turn affects the development of nephrocalcinosis. High calcium and high phosphate concentrations promote the precipitation of calcium phosphates in the test tube (Greenwald, 1945), this process being inhibited by the addition of magnesium (Boulet et al., 1962).
The type of dietary fiber may influence the development of nephrocalcinosis. Substitution of guar gum for cellulose in the diet has been shown to reduce the severity of nephrocalcinosis (Anderson et al., 1985). The aim of this study with female rats was to see whether the feeding of pectin, which shares characteristics with guar gum in that it also is a gelforming fiber, affects nephrocalcinogenesis. To obtain clues as to the mechanism underlying any effect of pectin on nephrocalcinosis, urinary concentrations of calcium, phosphorus and magnesium were determined.

\section{MATERIALS AND METHODS}

Animals, housing and diets: Female Wistar $\mathrm{Hsd} / \mathrm{Cpb}$ :WU rats, aged about 3 weeks, were used. On arrival, they were housed in groups of 4 animals in wire-topped, polycarbonate cages $(37.5 \times 22.5 \times 15.0 \mathrm{~cm})$ with a layer of sawdust as bedding. A commercial pelleted diet and tap water were supplied ad libitum.

Corresponding Author: Ahmed Alhaidary, Department of Animal Production, College of Food and Agricultural Sciences, King Saud University, P.O. Box 2460, Riyadh 11451, Kingdom of Saudi Arabia Tel: +966 14678475 Fax: +966 14678474 
Table 1: Composition of the experimental diets

\begin{tabular}{|c|c|c|c|c|c|}
\hline & \multicolumn{5}{|l|}{ Diet code $^{1}$} \\
\hline & $\begin{array}{l}0.2 \% \mathrm{P}^{2} \\
\text { cellulose }\end{array}$ & $\begin{array}{l}0.4 \% \mathrm{P} \\
\text { cellulose }\end{array}$ & $\begin{array}{l}0.4 \% \mathrm{P} \\
\text { pectin }\end{array}$ & $\begin{array}{l}0.6 \% \mathrm{P} \\
\text { cellulose }\end{array}$ & $\begin{array}{l}0.6 \% \mathrm{P} \\
\text { pectin }\end{array}$ \\
\hline \multicolumn{6}{|c|}{ Ingredients, g/100 g } \\
\hline Glucose & 63.95 & 63.28 & 63.35 & 62.61 & 62.68 \\
\hline Cellulose $^{3}$ & 10.00 & 10.00 & - & 10.00 & - \\
\hline Pectin $^{3}$ & - & - & 10.00 & - & 10.00 \\
\hline $\mathrm{CaCO}_{3}$ & 1.22 & 1.22 & 1.17 & 1.22 & 1.17 \\
\hline $\mathrm{NaH}_{2} \mathrm{PO}_{4} \cdot 2 \mathrm{H}_{2} \mathrm{O}$ & 0.50 & 1.51 & 1.50 & 2.52 & 2.51 \\
\hline $\mathrm{Na}_{2} \mathrm{CO}_{3}$ & 1.02 & 0.68 & 0.68 & 0.34 & 0.34 \\
\hline $\mathrm{MgCO}_{3}$ & 0.14 & 0.14 & 0.13 & 0.14 & 0.13 \\
\hline $\begin{array}{l}\text { Constant } \\
\text { components }\end{array}$ & 23.17 & 23.17 & 23.17 & 23.17 & 23.17 \\
\hline Total & 100.00 & 100.00 & 100.00 & 100.00 & 100.00 \\
\hline \multicolumn{6}{|c|}{ Chemical analysis, $\mathrm{g} / \mathbf{1 0 0} \mathrm{g}$} \\
\hline Dry matter & 92.500 & 89.500 & 91.900 & 92.50 & 92.500 \\
\hline Calcium & 0.440 & 0.440 & 0.440 & 0.430 & 0.420 \\
\hline Magnesium & 0.036 & 0.038 & 0.037 & 0.036 & 0.037 \\
\hline Phosphorus & 0.210 & 0.400 & 0.390 & 0.580 & 0.580 \\
\hline \multicolumn{6}{|c|}{ 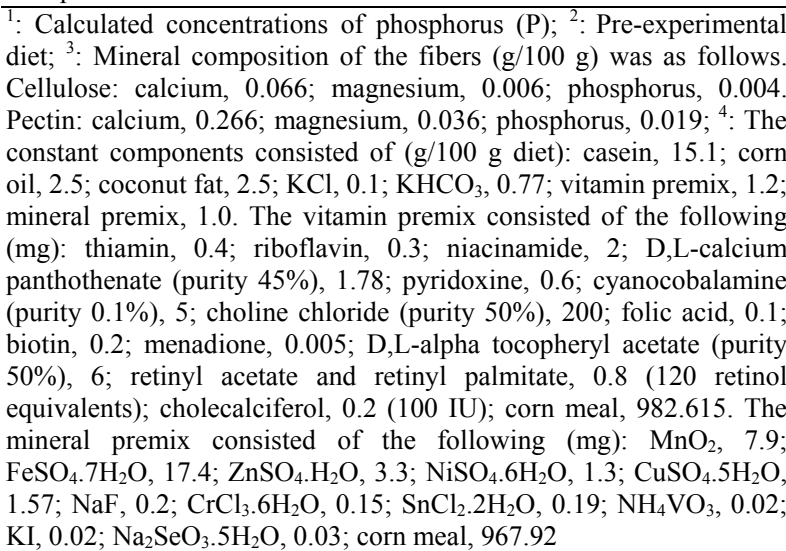 } \\
\hline
\end{tabular}

After 3 days, all rats received a purified, lowphosphorus diet (Table 1) and demineralized water ad libitum. After another 10 days (day 0 of the experiment), the rats were divided into 5 groups of similar body weight, consisting of 8 animals each. The groups were randomly assigned to the purified diets, including the pre-experimental, low-phosphorus diet (Table 1). The diets, which were in powdered form, were stored at $4^{\circ} \mathrm{C}$ until feeding. The animals had free access to feed and demineralized water. Body weights, feed and water intake were recorded. During the experimental period (days 0-28), the rats were housed individually in metabolism cages $\left(314 \mathrm{~cm}^{2} \times 12 \mathrm{~cm}\right)$. The cages were located in a room with controlled lighting (light, 07.00-19.00 h), temperature $\left(19-21^{\circ} \mathrm{C}\right)$ and relative humidity (45-55\%).

The low-phosphorus diet, which also served as preexperimental diet, contained $0.2 \%(\mathrm{w} / \mathrm{w})$ phosphorus and $10 \%$ cellulose (Arbocel B800; J. Rettenmeier and Söhne, Ellwangen, Germany). There were 4 diets (Table 1) containing either $0.4-0.6 \%$ phosphorus and either $10 \%$ cellulose or pectin (Medium Rapid Set $150^{\circ}$ SAG, Gelifiant pectin E 440a, Unipectine SA, 35600 Redon, France). It was anticipated that the $0.2 \%$ phosphorus diet would not produce nephrocalcinosis (Mars et al., 1988), thus serving as a negative control diet. The diets containing either $0.4-0.6 \%$ phosphorus were expected (Ritskes-Hoitinga et al., 1989) to induce varying degrees of nephrocalcinosis. This would increase the possibility to detect a fiber type effect, if any, on nephrocalcinogenesis. In addition, the use of diets differing in both the amount of phosphorus and type of fiber allows detection of interactions between the two dietary constituents. The diets were balanced for magnesium, calcium and phosphorus in the cellulose and pectin preparations (Table 1) so that any effects caused by differences in the mineral composition of the two fibers could be excluded. The glucose preparation (Morsweet 01934; Cerestar, Haubourdin, France) did not contain detectable amounts of minerals.

Collection of samples: On day 24 of the experiment, the cage parts below the wire-mesh bottom and the tubes for collection of urine and feces were rinsed with $0.1 \mathrm{M} \mathrm{HCl}$ and subsequently with demineralized water. To block bacterial and mould growth, $0.07 \mathrm{ml}$ of a $2 \%$ (w/v) sodium-azide solution was added daily to the urine collecting tubes. During days 25-27, urine and feces of each animal were collected quantitatively each day. Urine volume, $\mathrm{pH}$ and feces wet weight were determined. Urine and feces were then stored at $4^{\circ} \mathrm{C}$ until sample preparation.

At the end of the experiment (day 28), between 09.00-12.00 $\mathrm{h}$, the non-fasted rats were anaesthetized with diethyl ether and blood samples were taken by orbital puncture into heparinized tubes. Plasma was collected by low-speed centrifugation and stored at$20^{\circ} \mathrm{C}$ until analysis. Immediately after blood sampling, the anaesthetized animals were killed by cervical dislocation. Kidneys were removed and weighed after discarding the capsules. The right kidney was frozen at$20^{\circ} \mathrm{C}$ until chemical analysis. The left kidney was fixed in $10 \%$ formalin solution for histological analysis. Liver and cecum, including its contents, were also removed and weighed immediately.

Chemical analysis: Samples for mineral analyses were treated as follows. Freeze-dried samples of feces (about $150 \mathrm{mg}$ ) were ashed for $17 \mathrm{~h}$ at $500^{\circ} \mathrm{C}$ and extracted with $5 \mathrm{~mL}$ of $6 \mathrm{M} \mathrm{HCl}$ and brought to $50 \mathrm{~mL}$ with demineralized water. For complete recovery of phosphorus, the analysis of this mineral was performed at least 5 days after dissolving the ashed material in 
$\mathrm{HCl}$. Feed samples of about $750 \mathrm{mg}$ were ashed and treated for mineral analysis as feces. The right kidney was homogenized using an Ultra Turrax Type Tp 18/10 (Wilten Woltil BV, De Bilt, The Netherlands), in about $3 \mathrm{~mL}$ of demineralized water, dried at $105^{\circ} \mathrm{C}$, put in an ecsicator for $18 \mathrm{~h}$ and weighed again. The dried kidneys were completely ashed for $17 \mathrm{~h}$ at $500^{\circ} \mathrm{C}$ and processed as feces. Urine samples were acidified to $\mathrm{pH}=1$ with $6 \mathrm{M} \mathrm{HCl}$, centrifuged for $10 \mathrm{~min}(3000 \times \mathrm{g})$ and the supernatants were frozen at $-20^{\circ} \mathrm{C}$ until analysis.

Calcium and magnesium in diet, feces, urine and kidney samples were analyzed in the presence of $1 \%$ lanthanum-chloride by atomic absorption spectroscopy using a Varian AA-475 (Varian Techtron, Mulgrave, Australia). Calcium was measured at a wave length of $422.7 \mathrm{~nm}$ and air-acethylene ratio of 64:12. Magnesium was measured at a wavelength of $285.3 \mathrm{~nm}$ and an airacethylene ratio of 53:10. Total phosphorus was analyzed with a commercial test combination (ROCHE Phosphate) with the use of a CoBas-Bio auto-analyser (Hoffman-La Roche BV, Mijdrecht, the Netherlands).

Calcium and magnesium in plasma were analyzed in the presence of EDTA (final concentration, $0.075 \%$ ) by atomic absorption spectroscopy. Plasma phosphorus was analyzed enzymatically as described above. Urea in plasma was analyzed with a test combination kit from Hoffman-La Roche BV (Mijdrecht, The Netherlands).

Histological analysis: The fixed, left kidney of each animal was halved longitudinally, processed by conventional histological methods and embedded in paraffin wax. Sections of $5 \mu \mathrm{m}$ thickness were stained with hematoxylineosin. The severity of nephrocalcinosis of each section was scored randomly and blind using a scale from 0 (no calcium deposits) to 3 (severe calcinosis). Reference slides were used while scoring.

Statistical analysis: Student's t-test was used to evaluate differences between selected diet groups. In order to correct for the increasing probability of the type I error due to multiple comparisons, the criterion of significance was pre-set at $p<0.025$ or $p<0.017$. The distribution of the data was found to be normal with the use of Kolomogorov-Smirnov test and then Pearson linear $(r)$ correlation coefficients were calculated for the relationship between kidney calcium concentrations and nephrocalcinosis scores. Mann-Whitney $U$ test was used to compare histological scores of different diet groups. Two-way analysis of variance was used to identify effects of dietary phosphorus concentration, type of fiber and possible interactions. The probability of a type I error $<0.05$ was taken as the criterion of significance. All analyses were done using SPSS/PC software package (SPSS Inc, Chicago, USA).

\section{RESULTS}

Final body weights did not differ between the dietary groups (Table 2). Feed and water intake were significantly decreased by dietary pectin when compared with cellulose. The former effect was reflected by the intakes of calcium, magnesium and phosphorus (Table 3). Relative liver weight was significantly influenced by the amount of phosphorus and the type of fiber in the diet. An increased phosphorus intake with the cellulose diet increased liver weight, while substitution of pectin for cellulose in the high-phosphorus diet lowered liver weight. Pectin versus cellulose consistently caused an increased cecum weight (Table 2).

Kidney calcium concentrations and nephrocalcinosis scores for individual rats were significantly correlated $(r=+0.77, n=40 ; p<0.001)$. In rats fed the negative control diet, nephrocalcinosis was essentially absent (Table 2). Increasing the phosphorus concentration of the cellulose diet to either $0.4-0.6 \%$ significantly $(\mathrm{p}<0.017)$ increased kidney calcium concentrations and nephrocalcinosis scores. Magnesium and phosphorus concentrations in kidney were also increased by phosphorus loading. There was a significant interaction between dietary phosphorus concentration and type of fiber as to kidney weight and kidney mineral concentrations. In rats fed the $0.4 \%$ phosphorus diets, pectin versus cellulose significantly increased kidney calcium and phosphorus concentrations. No such effect was observed in rats fed the $0.6 \%$-phosphorus diets. On the contrary, group mean kidney concentrations of minerals were lower in rats fed pectin compared with those fed cellulose.

Plasma concentrations of calcium, magnesium and phosphorus were not influenced by the type of dietary fiber. However, group mean plasma urea concentrations were lower in rats fed pectin instead of cellulose. The difference reached statistical significance in rats fed the $0.4 \%$-phosphorus diet.

Urinary $\mathrm{pH}$ was significantly decreased by increased intakes of phosphorus, but was not influenced by the type of fiber (Table 3). Increasing dietary phosphorus concentrations and cellulose versus pectin increased urine output. When compared with the $0.2 \%$ phosphorus diet, the cellulose diets containing either $0.4-0.6 \%$ phosphorus caused significantly $(\mathrm{p}<0.017)$ decreased urinary calcium concentrations and excretion. There was no effect of 0.4 versus $0.6 \%$ phosphorus in the diet. The type of fiber did not affect calciuria. 
American J. Animal \& Vet. Sci., 5 (2): 111-116, 2010

Table 2: Growth performance, plasma mineral concentrations and nephrocalcinosis in rats fed the experimental diets

\begin{tabular}{|c|c|c|c|c|c|c|}
\hline & \multicolumn{6}{|l|}{ Diet $_{\text {code }}{ }^{1}$} \\
\hline & $0.2 \% \mathrm{P}^{2}$ cellulose & $0.4 \% \mathrm{P}$ cellulose & $0.4 \% \mathrm{P}$ pectin & $0.6 \% \mathrm{P}$ cellulose & $0.6 \% \mathrm{P}$ pectin & ANOVA \\
\hline \multicolumn{7}{|l|}{ Body weight, $g$} \\
\hline Initial, day 0 & $92.3 \pm 6.7$ & $92.3 \pm 7.4$ & $92.2 \pm 7.1$ & $92.4 \pm 6.8$ & $92.3 \pm 5.6$ & \\
\hline Final, day, 28 & $173.3 \pm 13.6$ & $177.1 \pm 8.7$ & $168.0 \pm 10.9$ & $174.1 \pm 12.3$ & $169.9 \pm 17.8$ & \\
\hline Relative liver weight, \% & $4.2 \pm 0.2$ & $4.0 \pm 0.2^{\mathrm{a}}$ & $3.9 \pm 0.1$ & $4.3 \pm 0.2^{\mathrm{a}, \mathrm{b}}$ & $3.9 \pm 0.3^{b}$ & $\mathrm{~F}, \mathrm{P}$ \\
\hline Relative cecal weight, $\%$ & $1.0 \pm 0.1$ & $1.1 \pm 0.2^{\mathrm{a}}$ & $2.0 \pm 0.4^{\mathrm{a}}$ & $1.1 \pm 0.1^{\mathrm{b}}$ & $2.5 \pm 0.4^{\mathrm{b}}$ & $\mathrm{F}, \mathrm{P} \times \mathrm{F}$ \\
\hline \multicolumn{7}{|l|}{ Intake } \\
\hline Feed, $g / 28$ days & $373.3 \pm 32.2$ & $372.9 \pm 23.6^{\mathrm{a}}$ & $335.4 \pm 20.4^{\mathrm{a}}$ & $359.6 \pm 18.7^{\mathrm{b}}$ & $323.6 \pm 32.6^{\mathrm{b}}$ & $\mathrm{F}$ \\
\hline Water, $\mathrm{ml} / 28$ days & $395.3 \pm 50.9$ & $429.0 \pm 83.0$ & $366.2 \pm 45.3$ & $479.9 \pm 88.0$ & $421.8 \pm 75.3$ & $\mathrm{~F}$ \\
\hline \multicolumn{7}{|l|}{ Plasma concentrations } \\
\hline Calcium, mg/100 mL & $11.0 \pm 0.6$ & $11.0 \pm 0.5$ & $11.0 \pm 0.5$ & $11.2 \pm 0.5$ & $10.9 \pm 0.5$ & \\
\hline Magnesium, mg/100 mL & $1.6 \pm 0.2$ & $1.5 \pm 0.1$ & $1.5 \pm 0.1$ & $1.4 \pm 0.3$ & $1.5 \pm 0.1$ & \\
\hline Phosphorus, mg/100 mL & $53.0 \pm 9.3$ & $64.0 \pm 5.8$ & $64.7 \pm 6.3$ & $65.8 \pm 8.4$ & $64.1 \pm 6.0$ & \\
\hline Urea, mmol L ${ }^{-1}$ & $6.5 \pm 0.5$ & $6.1 \pm 0.4^{\mathrm{a}}$ & $5.2 \pm 0.6^{\mathrm{a}}$ & $8.1 \pm 2.2$ & $7.0 \pm 1.9$ & $\mathrm{P}$ \\
\hline \multicolumn{7}{|l|}{ Kidney measures } \\
\hline $\begin{array}{l}\text { Relative weight, } \% \\
\text { (g/100 g body weight) }\end{array}$ & $0.4 \pm 0.0$ & $0.4 \pm 0.0^{\mathrm{a}}$ & $0.4 \pm 0.0^{\mathrm{b}}$ & $0.6 \pm 0.0^{\mathrm{a}}$ & $0.5 \pm 0.1^{\mathrm{b}}$ & $\mathrm{P}, \mathrm{P} \times \mathrm{F}$ \\
\hline Dry weight, $\mathrm{mg}$ & $147.7 \pm 10.8$ & $162.5 \pm 15.2^{\mathrm{a}}$ & $180.2 \pm 19.8$ & $255.3 \pm 31.2^{\mathrm{a}, \mathrm{b}}$ & $209.5 \pm 29.1^{\mathrm{b}}$ & $\mathrm{P}, \mathrm{P} \times \mathrm{F}$ \\
\hline Calcium, $\%$ of dry weight & $0.1 \pm 0.0$ & $3.1 \pm 1.2^{\mathrm{a}, \mathrm{b}}$ & $5.2 \pm 1.7^{\mathrm{a}}$ & $9.0 \pm 2.3^{\mathrm{b}}$ & $6.6 \pm 1.4$ & $\mathrm{P}, \mathrm{P} \times \mathrm{F}$ \\
\hline Magnesium, $\%$ of dry weight & $0.1 \pm 0.0$ & $0.2 \pm 0.0^{\mathrm{a}}$ & $0.2 \pm 0.0$ & $0.3 \pm 0.1^{\mathrm{a}}$ & $0.2 \pm 0.0$ & $\mathrm{P}, \mathrm{P} \times \mathrm{F}$ \\
\hline Phosphorus, $\%$ of dry weight & $1.3 \pm 0.0$ & $2.5 \pm 0.7^{\mathrm{a}, \mathrm{b}}$ & $3.7 \pm 0.7^{\mathrm{a}}$ & $5.4 \pm 1.0^{\mathrm{b}}$ & $4.3 \pm 0.7$ & $\mathrm{P}, \mathrm{P} \times \mathrm{F}$ \\
\hline Histological score & $0.0 \pm 0.0$ & $2.0 \pm 1.0$ & $2.0 \pm 1.0$ & $3.0 \pm 1.0$ & $3.0 \pm 0.0$ & \\
\hline
\end{tabular}

Table 3: Mineral excretion and absorption in rats fed the experimental diets

\begin{tabular}{|c|c|c|c|c|c|c|}
\hline & \multicolumn{6}{|l|}{ Diet code $^{1}$} \\
\hline & $0.2 \% \mathrm{P}^{2}$ cellulose & $0.4 \% \mathrm{P}$ cellulose & $0.4 \% \mathrm{P}$ pectin & $0.6 \% \mathrm{P}$ cellulose & $0.6 \% \mathrm{P}$ pectin & ANOVA \\
\hline \multicolumn{7}{|l|}{ Urine } \\
\hline $\mathrm{pH}$ & $9.2 \pm 0.2$ & $9.0 \pm 3.0$ & $9.0 \pm 0.1$ & $8.4 \pm 1.0$ & $7.8 \pm 1.1$ & $\mathrm{P}$ \\
\hline Production, $\mathrm{ml}$ day $^{-1}$ & $7.1 \pm 2.9$ & $9.1 \pm 3.6$ & $6.2 \pm 1.4$ & $11.2 \pm 3.1$ & $9.4 \pm 3.4$ & $\mathrm{P}, \mathrm{F}$ \\
\hline \multicolumn{7}{|l|}{ Faeces } \\
\hline Wet weight, $\mathrm{g} \mathrm{day}^{-1}$ & $2.3 \pm 0.2$ & $2.3 \pm 0.2^{\mathrm{a}}$ & $1.6 \pm 0.7^{\mathrm{a}}$ & $2.5 \pm 0.3^{\mathrm{b}}$ & $1.4 \pm 0.4^{\mathrm{b}}$ & $\mathrm{F}$ \\
\hline Dry weight, $\mathrm{g} \mathrm{day}^{-1}$ & $1.5 \pm 0.1$ & $1.5 \pm 0.2^{\mathrm{a}}$ & $0.9 \pm 0.3^{\mathrm{a}}$ & $1.5 \pm 0.1^{\mathrm{b}}$ & $0.6 \pm 0.2^{\mathrm{b}}$ & $\mathrm{F}$ \\
\hline \multicolumn{7}{|l|}{ Calcium } \\
\hline Intake, $\mathrm{mg} \mathrm{day}^{-1}$ & $59.0 \pm 6.2$ & $57.5 \pm 4.3$ & $54.5 \pm 2.6$ & $54.7 \pm 4.0$ & $48.7 \pm 6.1$ & $\mathrm{P}, \mathrm{F}$ \\
\hline Urine, $\mathrm{mg} \mathrm{day}^{-1}$ & $1.0 \pm 0.5$ & $0.3 \pm 0.1$ & $0.3 \pm 0.1$ & $0.2 \pm 0.1$ & $0.3 \pm 0.2$ & \\
\hline Urine, $\mathrm{mg} \mathrm{mL}^{-1}$ & $0.2 \pm 0.1$ & $0.0 \pm 0.0$ & $0.0 \pm 0.0$ & $0.0 \pm 0.0$ & $0.0 \pm 0.0$ & \\
\hline Apparent absorption, mg day ${ }^{-1}$ & $26.5 \pm 5.5$ & $26.6 \pm 4.3$ & $26.3 \pm 8.0$ & $24.3 \pm 4.8$ & $21.2 \pm 4.2$ & \\
\hline \multicolumn{7}{|l|}{ Magnesium } \\
\hline Intake, $\mathrm{mg} \mathrm{day}^{-1}$ & $4.8 \pm 0.5$ & $5.0 \pm 0.4$ & $4.6 \pm 0.2$ & $4.6 \pm 0.3$ & $4.3 \pm 0.5$ & $\mathrm{P}, \mathrm{F}$ \\
\hline Urine, mg day ${ }^{-1}$ & $1.3 \pm 0.4$ & $0.8 \pm 0.4$ & $0.6 \pm 0.2$ & $0.6 \pm 0.2$ & $0.8 \pm 0.5$ & \\
\hline Urine, $\mathrm{mg} \mathrm{mL}^{-1}$ & $0.2 \pm 0.1$ & $0.1 \pm 0.1$ & $0.1 \pm 0.0$ & $0.1 \pm 0.0$ & $0.1 \pm 0.1$ & \\
\hline Apparent absorption, mg day ${ }^{-1}$ & $2.7 \pm 0.3$ & $2.5 \pm 0.5^{\mathrm{a}}$ & $2.5 \pm 0.7$ & $1.9 \pm 0.3^{\mathrm{a}}$ & $2.3 \pm 0.5$ & $\mathrm{P}$ \\
\hline \multicolumn{7}{|l|}{ Phosphorus } \\
\hline Intake, $\mathrm{mg} \mathrm{day}^{-1}$ & $28.1 \pm 3.0$ & $52.3 \pm 3.9^{\mathrm{a}}$ & $48.3 \pm 2.3^{\mathrm{b}}$ & $73.9 \pm 5.4^{\mathrm{a}}$ & $67.3 \pm 8.5^{\mathrm{b}}$ & $\mathrm{P}, \mathrm{F}$ \\
\hline Urine, $\mathrm{mg} \mathrm{day}^{-1}$ & $3.2 \pm 2.9$ & $16.9 \pm 1.6^{\mathrm{a}}$ & $17.2 \pm 3.2^{\mathrm{b}}$ & $34.0 \pm 4.1^{\mathrm{a}}$ & $35.1 \pm 8.3^{\mathrm{b}}$ & $\mathrm{P}$ \\
\hline Urine, $\mathrm{mg} \mathrm{mL}^{-1}$ & $0.5 \pm 0.5$ & $2.2 \pm 0.8^{\mathrm{a}}$ & $2.9 \pm 0.6^{\mathrm{b}}$ & $3.2 \pm 0.8^{\mathrm{a}}$ & $3.9 \pm 0.7^{b}$ & $\mathrm{P}, \mathrm{F}$ \\
\hline Apparent absorption, $\mathrm{mg} \mathrm{day}^{-1}$ & $17.5 \pm 2.5$ & $35.4 \pm 3.2^{\mathrm{a}}$ & $35.9 \pm 4.9^{\mathrm{b}}$ & $55.0 \pm 4.4^{\mathrm{a}}$ & $52.9 \pm 7.3^{\mathrm{b}}$ & $\mathrm{P}$ \\
\hline
\end{tabular}

Values are means \pm SD for 8 rats per dietary group. Values within the same row sharing the same superscript are significantly different $(p<0.025)$. The column under ANOVA indicates significant effects $(p<0.05)$ based on two-way analysis of variance (the group fed the $0.2 \%$ phosphorus diet was not included): $\mathrm{P}=$ phosphorus effect; $\mathrm{F}=$ effect of fiber; $\mathrm{P} \times \mathrm{F}=$ effect of interaction. ${ }^{1}$ : Calculated concentrations of phosphorus (P); ${ }^{2}$ : Pre-experimental diet

For urinary excretion of magnesium a similar pattern was seen. Increasing intakes of phosphorus were associated with increasing rates of urinary phosphorus excretion. The type of fiber did not influence absolute 
phosphorus output with urine, but in rats fed pectin versus cellulose phosphorus concentrations in urine were significantly increased.

Pectin versus cellulose significantly reduced fecal excretion of dry matter. Excretion of calcium with feces (not shown), apparent calcium absorption (Table 3) and retention (not shown) were not influenced by the amount of phosphorus and the type of fiber in the diet. Pectin in the diet significantly lowered fecal excretion of magnesium when compared with cellulose (not shown), but apparent absorption (Table 3 ) and retention of magnesium (not shown) were not significantly influenced. An increasing intake of phosphorus with the cellulose diet was associated with significantly lowered apparent magnesium absorption. Fecal excretion of phosphorus in rats fed the cellulose diets was only slightly, but significantly, increased when the dietary phosphorus concentrations were increased from 0.4 to $0.6 \%$ (not shown). Pectin versus cellulose tended to lower fecal phosphorus excretion (not shown), but there was no effect on apparent phosphorus absorption (Table 3).

\section{DISCUSSION}

In female rats fed purified diets containing a phosphorus concentration of $0.4 \%$, pectin in the diet versus cellulose produced a significant increase in kidney concentrations of calcium and phosphorus. This nephrocalcinogenic effect of pectin was not seen in rats fed diets containing $0.6 \%$ phosphorus. Increasing the amount of phosphorus in the diet from $0.4-0.6 \%$, produces massive nephrocalcinosis (Ritskes-Hoitinga et al., 1989; Van Camp et al., 1990), an effect that was confirmed by the present study. Possibly, high phosphorus intakes override the differential effect of pectin and cellulose on nephrocalcinogenesis.

The nephrocalcinogenic activity of pectin as observed in the present study may not have been anticipated. Dietary guar gum, which is a gel-forming fiber like pectin, has been reported to dampen nephrocalcinogenesis when compared with cellulose (Anderson et al., 1985). However, in that study the mineral concentrations of the fiber preparations and the complete diets were not shown. In addition, it was not mentioned whether the diets were balanced for differences in mineral composition of the fiber preparations. Thus, it cannot be excluded that the observed (Anderson et al., 1985) effect of guar gum versus cellulose was caused by differences in mineral intake. In the present study, the diets were carefully balanced for residual calcium, phosphorus and magnesium in the pectin and cellulose preparations, even though the concentrations of these minerals were relatively low. The analyzed mineral concentrations in the complete diets (Table 1) indicated that the pectin and cellulose diets were comparable in this respect.

In an attempt to obtain clues concerning the mechanism of action of the nephrocalcinogenic effect of pectin, we have measured mineral excretion. The major determinants of nephrocalcinogenesis are low magnesium intakes (Bunce et al., 1965), high phosphorus intakes and high calcium intakes (Hoek et al., 1988). Thus, it could be suggested that pectin inhibits the absorption of magnesium and/or stimulates the absorption of phosphorus and/or calcium when compared with cellulose in diets containing $0.4 \%$ phosphorus. However, pectin versus cellulose was not found to alter the apparent absorption of calcium, magnesium and phosphorus. This corroborates the view that purified fiber sources may not influence mineral absorption (Munoz, 1986). Thus, there is no evidence that the nephrocalcinogenic effect of pectin is caused by changing the availability of magnesium, calcium and phosphorus from the diet.

The concentrations in urine of magnesium, calcium and phosphorus may be indicative of those in the tubular fluid and thus relate to the intratubular formation of calcium phosphate precipitates, that is nephrocalcinosis. High concentrations of calcium and phosphorus will stimulate nephrocalcinogenesis, whereas high magnesium concentrations can be expected to inhibit this process (Greenwald, 1945; Boulet et al., 1962). As mentioned above, feeding experiments with diets differing in the contents of calcium, phosphorus and/or magnesium are in line with this reasoning. Pectin versus cellulose in $0.4 \%$ phosphorus diets did not influence calcium and magnesium concentrations in urine, but it raised phosphorus concentrations. Thus, pectin may have stimulated by nephrocalcinogenesis by elevating phosphorus concentrations in urine.

Acidification of urine by either feeding a high-protein diet (Van Camp et al., 1990) or a diet with ammonium chloride (Kootstra et al., 1991) is associated with inhibition of nephrocalcinogenesis. However, pectin did not systematically alter urinary $\mathrm{pH}$ when compared with cellulose. It would thus seem that dietary pectin does not influence the development of nephrocalcinosis through an effect on urinary $\mathrm{pH}$.

\section{CONCLUSION}

Pectin versus cellulose in diets containing $0.4 \%$ phosphorus was found to stimulate 
nephrocalcinogenesis in female rats. Pectin-induced nephrocalcinogenesis was associated with an increased concentration of phosphorus in urine.

\section{REFERENCES}

Anderson, R.L., R.L. Kanerva and W.R. Francis, 1985. Effect of dietary fiber composition on renal mineralization in female rats ingesting purified diet-AIN TM ${ }^{76}$. Nutr. Rep. Int., 31: 1331-1339.

Boulet, M., J.R. Marier and D. Rose, 1962. Effect of magnesium on formation of calcium phosphate precipitates. Arch. Biochem. Biophys., 96: 629-636. PMID: 13871819

Bunce, G.E., H.E. Sauberlich, P.G. Reeves and T.S. Oba, 1965. Dietary phosphorus and magnesium deficiency in the rat. J. Nutr., 86: 406-414. PMID: 14329521

Greenwald, I., 1945. The effect of phosphate on solubility of calcium carbonate and of bicarbonate on the solubility of calcium and magnesium phosphates. J. Biol. Chem., 161: 697-704.

Hoek, A.C., A.G. Lemmens, J.W.M.A. Mullink and A.C. Beynen, 1988. Influence of dietary calcium: Phosphorus ratio on mineral excretion and nephrocalcinosis female in rats. J. Nutr., 118: 1210-1216. PMID: 3183767
Kootstra, Y., J. Ritskes-Hoitinga, A.G. Lemmens and A.C. Beynen, 1991. Diet-induced calciuria and nephrocalcinosis in female rats. Int. J. Vit. Nutr. Res., 61: 100-101. PMID: 1856039

Mars, Y.W.H.M., A.G. Lemmens and A.C. Beynen, 1988. Dietary phosphorus and nephrocalcinosis in female rats. Nutr. Rep. Int., 38: 249-258.

Munoz, J.M., 1986. Overview of the Effects of Dietary Fiber on the Utilization of Minerals and Trace Elements. In: Handbook of Dietary Fiber in Human Nutrition, Spiller, G.A. (Ed.). CRC Press Inc., Boca Raton, FL, USA., pp. 193-200.

Nguyen, H.T. and J.C. Woodard, 1980. Intranephronic calculosis in rats-an ultrastructural study. Am . J. Pathol., 100: 39-57. PMID: 7395968

Ritskes-Hoitinga, J., A.G. Lemmens, L.H.J.C. Danse and A.C. Beynen, 1989. Phosphorus-induced nephrocalcinosis and kidney function in female rats. J. Nutr., 119: 1423-1431. PMID: 2585132

Ritskes-Hoitinga, J., J.N.J.J. Mathot, L.H.J.C. Danse and A.C. Beynen, 1991. Commercial rodent diets and nephrocalcinosis in weanling female rats. Lab. Anim., 25: 126-132. PMID: 1857094

Van Camp, I., J. Ritskes-Hoitinga, A.G. Lemmens and A.C. Beynen, 1990. Diet-induced nephrocalcinosis and urinary excretion of albumin in female rats. Lab. Anim., 16: 130-132. PMID: 2142229 